\title{
Opioid Use Stigma: An Examination of Student Attitudes on Harm Reduction Strategies
}

\author{
Gemma Reynolds ${ }^{1}$ (D) $\cdot$ Brittany L. Lindsay $^{1}$ (D) Stephanie Knaak ${ }^{2}$. \\ Andrew C. H. Szeto ${ }^{1}$ (D)
}

Accepted: 11 January 2022 / Published online: 20 January 2022

(c) The Author(s), under exclusive licence to Springer Science+Business Media, LLC, part of Springer Nature 2022

\begin{abstract}
Understanding how the public views harm reduction strategies may help inform researchers on how to reduce related stigma and barriers to help-seeking. The current study explored whether stigma towards those who use opioids was affected by gender and type of harm reduction strategy used. Undergraduate students $(N=328)$ were randomly assigned to read one of six vignettes varying by gender and the type of harm reduction strategy: no harm reduction, opioid agonist therapy (OAT), or safe consumption sites (SCSs). Results demonstrated that participants were less stigmatizing towards the character who engaged in OAT compared to the character with no harm reduction. There was also a pattern demonstrating that SCSs may be perceived more negatively than OAT, although these differences only met conventional significance, not adjusted/corrected alphas. There were no significant effects for gender. Qualitative results revealed that participants held misconceptions about harm reduction. Implications and future directions are discussed.
\end{abstract}

Keywords Harm reduction · Addiction · Opioids · Public stigma - Safe consumption sites · Opioid agonist therapy

Countries around the world have been experiencing an escalating public health crisis related to the misuse of opioids for well over a decade. Between 1999 and 2017, there were 399,230 opioid-related deaths in the USA, with the deaths in 2015-2017 contributing to the decrease in life expectancy for the first time in over 60 years (OECD, 2019). Furthermore, the onset of the COVID-19 pandemic has worsened this crisis. In Canada, between April and December 2020, 5,148 opioid-related deaths occurred. This is an $89 \%$ increase from the same time period in 2019 (2,722 deaths from April to December 2019; Special Advisory Committee on the Epidemic of Opioid Overdoses, 2021). Within this context, harm reduction has become a public health priority as it includes policies, practices, and programs that aim to reduce the negative impact of the drug use, without necessarily

Brittany L. Lindsay

bllindsa@ucalgary.ca

1 Department of Psychology, University of Calgary, 2500 University Dr NW, Calgary, AB T2N 1N4, Canada

2 Department of Psychiatry and Faculty of Nursing, University of Calgary, Calgary, Canada 
stopping drug use itself (Harm Reduction International, n.d.). The stigma of addiction (and the opposition to harm reduction) acts as a barrier to implementation and access of harm reduction services. Since stigma is one of the biggest barriers to help-seeking behaviours (e.g. Corrigan et al., 2014; Henderson et al., 2013), more knowledge is needed to better understand the nuances of stigma related to opioid use and harm reduction, along with how it appears in different contexts. The current study aims to contribute to the understanding of harm reduction and opioid-related stigma by investigating whether the stigma towards those who use opioids differs based on the harm reduction strategies they are implementing (or not), and whether gender plays a contributing role.

According to Link and Phelan (2001), stigma is a process by which individual differences are labelled, which can then lead to negative stereotypes, separation, status loss, subsequent discrimination, and disadvantages related to education, employment, or basic necessities (such as housing and healthcare; Corrigan \& Shapiro, 2010). Stigma exists at three levels: self, structural, and public (e.g. Knaak et al., 2017; Livingston, 2020). Selfstigma occurs when the individual internalizes the negative perceptions or stereotypes about their condition or attribute, which leads to decrements in self-efficacy and self-worth (Corrigan \& Rao, 2012). Structural stigma refers to the policies and practices of public or private institutions that purposely or unintentionally create or uphold inequalities (Livingston, 2013). The current study aimed to examine the last type of stigma: public stigma. Public stigma occurs when members of the public accept, endorse, and reproduce negative stereotypes and beliefs towards the individual(s) in question (Corrigan \& Shapiro, 2010).

Research has suggested that the stigma between substance use disorders (SUDs) and other types of mental illnesses can differ greatly, in that SUDs tend to be perceived more negatively than other mental illnesses (Barry et al., 2014; Mannarini \& Boffo, 2015; Mushtaq et al., 2015). Additionally, stigma towards males with a SUD has been viewed in a much more negative light than females (Goodyear et al., 2018; Sattler et al., 2017; Weeks \& Stenstrom, 2020), which could be a result of gender-typical illnesses (i.e. a male with an addiction, a female with depression) being perceived more negatively (and taken less seriously) than if the illness is gender atypical (Wirth \& Bodenhausen, 2009). Much of the literature conducted on the stigma of SUDs has focused on alcohol use and/or substance use in general (Barry et al., 2014; Mannarini \& Boffo, 2015; Wirth \& Bodenhausen, 2009). However, literature on other drug classes, such as opioids, is lacking.

Although there has been some research done on the stigma of opioid use specifically (e.g. Stuart, 2019), it has not been extensively studied. It is thought that opioid stigma may differ from the stigma of other types of substances due to their ambiguous legal status and the fact they involve both illegal drugs (e.g. heroin) and legal drugs (e.g. oxycodone, codeine) that can also be used and purchased illegally (Kennedy-Hendricks et al., 2017). Related to these legality differences, research has found that the misuse of a prescribed opioid, Vicodin (i.e. legal), was perceived more favourably than the misuse of non-prescribed Vicodin or heroin (i.e. illegal); however, heroin was the most stigmatized (Weeks $\&$ Stenstrom, 2020). Related to harm reduction for opioid use, one study found that injecting drug users reported feeling stigmatized by pharmacy staff when not necessarily engaging in treatment, but while accessing the needle exchange program (NEP), which is a form of harm reduction (Simmonds \& Coomber, 2009). Thus, the stigma surrounding opioid use may deter opioid users from accessing services that reduce the harms of their drug using behaviour (McGinty \& Barry, 2020).

Alongside NEPs, other common harm reduction strategies related to opioid use include opioid agonist therapy (OAT) and safe consumption sites (SCSs). OAT is known as an effective treatment for opioid addiction and involves taking a full agonist (methadone) or a 
partial agonist (buprenorphine) that bind to the opioid receptors to prevent withdrawals and cravings, but do not produce a euphoric high when used properly (Centre for Addiction and Mental Health, 2016). The aim of OAT is to wean off the maintenance medication eventually, but in cases of serious and long-term opioid use, a patient may need OAT indefinitely (National Institute on Drug Abuse, 2020b) and therefore, can be considered a form of harm reduction. SCSs are places where people go to consume their pre-obtained drugs under the supervision of trained medical staff. The staffs are there in case of overdose, cardiac arrest, or allergic reactions, thereby reducing the strain on emergency medical services (Health Canada, 2020b).

There is some evidence suggesting that certain harm reduction strategies may be more stigmatized than others. Previous literature has demonstrated that OAT has been perceived as being much more acceptable than SCSs among addiction agencies (Rosenberg \& Phillips, 2003). In a study by Javadi et al. (2021), 80.5\% of substance use treatment professionals thought that OAT would benefit public health, as opposed to only $64.9 \%$ thinking the same with SCSs. Additionally, since the public tends to endorse the notion of "not in my back yard" (NIMBY) when it comes to the implementation of services that tend to serve the disadvantaged (such as homeless shelters, jails, halfway houses, etc.; Dear, 1992), this may suggest that public stigma may increase towards specific harm reduction programs (such as SCSs) in one's community. This was seen in Javadi et al.'s (2021) study, where only $28.1 \%$ of respondents said they would feel comfortable if a SCS opened in their neighbourhood.

Due to harm reduction not being centred on abstinence, there is much controversy surrounding its policies and programs (Csiernik et al., 2017; MacCoun, 1998; Watson et al., 2012). Limited research has examined the relationship between support for harm reduction and the stigma towards individuals who use drugs. A US study demonstrated that participants with a higher level of stigma towards those who used opioids also demonstrated lower support for the implementation of harm reduction programs (which included NEPs and SCSs; McGinty et al., 2018). Another study by Baker et al. (2019) found that individuals who stigmatized people who injected drugs were less likely to support the implementation of harm reduction programs. Since public opinions and support have a major impact on policy decisions (Burstein, 2003) and the success of harm reduction initiatives is often reliant on community support (Davis et al., 2018), it may prove beneficial to understand the public's stigma towards those who use opioids and the different harm reduction strategies that may be utilized. By examining if stigma towards these individuals differs depending on the harm reduction strategy, this may lead to a better understanding on perceptions towards opioid use and harm reduction.

\section{The Current Study}

The present study aimed to examine the stigma towards opioid use and different harm reduction strategies, alongside possible gender effects. University student participants were randomly assigned to read one of six vignettes that described a character (male or female) who used opioids and the respective harm reduction strategy they engaged in (OAT, SCSs, no harm reduction), and their perceptions of this character were collected. Several hypotheses were considered:

H1: Stigma towards the character who used OAT would be lower than both no harm reduction (H1a) and SCS (H1b). 
$\mathrm{H} 2$ : Stigma towards the character in the SCS condition would be higher than no harm reduction.

H3: Stigma towards the male character would be higher compared to the female character in all conditions.

Due to the lack of literature on the topic, no specific predictions on interaction effects were made; however, they were explored. Additionally, open-ended questions were added at the end to obtain more insight into participants' understanding of harm reduction, OAT, and SCSs. This study was pre-registered on AsPredicted (\#55522) on January 8, 2021.

\section{Method}

\section{Participants}

The current study utilized a convenience sample of undergraduate students, who were recruited through an online research participation system at the University of Calgary. A requirement of this system is that students are enrolled in at least one psychology course that term, as students were remunerated $0.5 \%$ bonus course credit for their participation. To determine adequate final sample size, an a priori power analysis was conducted using G*Power $3.1(f=0.25,1-\beta=0.95, \alpha=0.017, N=342$; Faul et al., 2009). A total of 361 participants were recruited. Any participants with unsuitable data or questionable results (e.g. selected "neutral" on every item in a scale, failed manipulation checks, did not reconsent after debriefing, etc.) had their data excluded $(n=33)$. This resulted in a final sample size of $328(N=328)$. The final sample had a mean age of $20.05(S D=3.77$; range $=17-57)$, with about $50 \%$ identifying as female $(n=165)$ and $49 \%$ identifying as male ( $n=161$; one non-binary person). The sample had diversity in ethnicity, year of study, and academic major (see Table 1).

\section{Ethics Approval and Informed Consent}

All participants provided informed consent before the study began and then reconsented to their data being used in the research after they were debriefed. The current study was approved by The University of Calgary's Conjoint Faculties Research Ethics Board (REB20-1381) which aligns with the Tri-Council Policy Statement: Ethical Conduct for Research Involving Humans.

\section{Materials}

\section{Vignettes}

There were six different researcher-created vignettes involving the three harm reduction strategies (no harm reduction, OAT, SCS), each with a male ("John") and female ("Tammy") version. All vignettes described a 30-year-old individual with a full-time job, a spouse, and a dog (i.e. an average person with responsibilities and relationships). The individual has an opioid use problem and was not willing to quit using opioids. It was 
Table 1 Characteristic responses of student sample

\begin{tabular}{lll}
\hline Characteristic & Response & $n(\%)$ \\
\hline Ethnicity & White & $90(27 \%)$ \\
& Southeast Asian & $82(25 \%)$ \\
& East Asian & $53(16 \%)$ \\
& Filipino & $29(9 \%)$ \\
& Mixed & $17(5 \%)$ \\
& Arab/West Asian & $16(5 \%)$ \\
& Latin, Central, South American & $14(4 \%)$ \\
& Black & $11(3 \%)$ \\
Oear of study & First year & $15(5 \%)$ \\
& Second year & $166(51 \%)$ \\
& Third year & $75(23 \%)$ \\
& Fourth year or higher & $59(18 \%)$ \\
Psychology & $27(8 \%)$ \\
& Kinesiology & $77(24 \%)$ \\
& Biological sciences & $29(9 \%)$ \\
& Open studies/undeclared & $27(8 \%)$ \\
& Other major (37 different majors) & $164(50 \%)$ \\
\hline
\end{tabular}

$N \mathrm{~s}=325-327$ as some students chose not to answer certain demographic questions

explained that the individual engaged in OAT, visited a SCS, or did not engage in any harm reduction at all.

\section{Measures}

Social Distance A modified Social Distance Scale for Substance Users (SDS-SU; Brown, 2011; modified from Link et al., 1987) was used to measure participants' desire for social distance from the vignette character. This is a 7-item scale that asks participants how willing they are to interact with the vignette character (e.g. "How would you feel about having John as a neighbour?") using a 4-point Likert-like scale ( $1=$ definitely willing to $4=$ definitely unwilling). The current study replaced Brown's (2011) use of "someone with a substance use problem" with the vignette characters' names. A composite mean score was created, so that higher scores indicate higher desire for social distance. The SDS-SU demonstrated good internal consistency in previous literature $(\alpha=0.85$; Brown, 2011) and the current study $(\alpha=0.86)$.

Semantic Differential To measure participant's feelings and emotions towards the vignette character, a modified version of the Affect Scale for Substance Users (AS-SU; Brown, 2011; modified from Penn et al., 1994) was used. The AS-SU asks participants to indicate how they feel towards interacting with the vignette character on 10 word pairs (e.g. supportive vs. resentful, empathetic vs. angry) on a 7-point scale (e.g. $1=$ supportive, $7=$ resentful). Items were reverse coded as necessary and a composite mean score was created for each participant, with higher scores indicating greater negative affect towards the 
character. The AS-SU has shown good to excellent internal consistency ( $\alpha=0.92$; Brown, $2011 ; \alpha=0.89$; current study).

Attribution To assess stigmatizing and discriminatory attitudes towards the vignette character, a modified version of the Attribution Questionnaire (AQ-27; Corrigan et al., 2003) was used. The AQ-27 measures participants' attitudes and beliefs towards a person with a mental illness and contains 27 items on a 9-point Likert-like scale $(1=$ not at all to $9=$ very mисh) assessing nine domains (three items each) of mental illness stigma according to attribution theory: blame, anger, pity, help, dangerousness, fear, avoidance, segregation, and coercion. Three items in this study were adapted from the original AQ-27: the words "psychiatric hospital" (item 15), "asylum" (item 17), and "group home" (item 25) were changed to "rehab centre". The current study used an overall mean score, with the help and avoidance items reverse coded so that a higher overall score indicated a greater level of stigma that the participant had towards the character. In previous literature, the Cronbach's alpha for the whole scale has demonstrated good internal consistency (e.g. $\alpha=0.88$; Martínez-Hidalgo et al. 2018), consistent with the current study ( $\alpha=0.89)$.

\section{Additional Measures and Questions}

Additional measures were included in the survey as potential covariates. ${ }^{1}$ Previous literature has suggested that familiarity with a mental illness can mitigate stigma (Aflakseir et al., 2019); hence, the Level of Contact Report (LCR; Holmes et al., 1999) was used. The other covariate was a question from Alexander and Link (2003) assessing political conservatism and asked participants how they would describe themselves politically on a 5-point scale $(1=$ very liberal, $3=$ moderate, $5=$ very conservative $)$, since those who identify as more politically conservative tend to have more stigmatizing views towards those with a SUD (Barry \& McGinty, 2014; Broady et al., 2020).

To gauge participants' pre-existing knowledge on harm reduction, three items that asked participants how they would rate their knowledge of harm reduction, OAT, and SCSs were included. These items were based on previous research that asked about participants' selfreported knowledge of harm reduction programs (Baker et al., 2019); however, the current study used a 7-point Likert-like scale $(1=$ no knowledge, $4=$ some knowledge, $7=$ very knowledgeable). Three open-ended response questions were also presented, asking participants to explain their understanding of harm reduction, OAT, and SCSs. Participants were also asked basic demographic questions (age, gender, ethnicity, year of study, and academic major).

\section{Procedure}

Participants were presented with an anonymous link that redirected them to an online survey (hosted by Qualtrics; https://www.qualtrics.com) and were presented with the consent form. After providing informed consent, participants were given a definition of what

\footnotetext{
1 The Opening Minds Provider Attitudes Towards Opioid Use Scale (OM-PATOS; Knaak \& Stuart, 2021) was originally included in the survey as a potential covariate, but it was realized post-hoc that the measure was too similar in construct to the dependent measures (but measured before the experimental manipulation) and was not used in the study.
} 
Table 2 Pearson's correlations of dependent variables and covariates

\begin{tabular}{llllllll}
\hline Measure & Mean & SD & 1 & 2 & 3 & 4 & 5 \\
\hline 1. Social distance & 2.86 & 0.55 & $\mathbf{. 8 6}$ & & & \\
2. Semantic differential & 3.49 & 0.90 & $.65^{* *}$ & .89 & & \\
3. Attribution & 4.42 & 0.97 & $.73^{* *}$ & $.73^{* *}$ & .89 & \\
4. Political conservatism & 2.48 & 1.03 & $.33^{* *}$ & $.24^{* *}$ & $.25^{* *}$ & - & -.08 \\
5. LCR & 4.82 & 2.53 & -.10 & $-.15^{*}$ & $-.14^{*}$ & - \\
\hline
\end{tabular}

Cronbach's alpha for the current study is presented across the diagonal (bolded) when appropriate. $S D$, standard deviation. $* p<.05, * * p<.001$

opioids are and described their legality, the different types, how they can be consumed, what they are used for, and an explanation of an "opioid use problem". Information for this definition was taken from a variety of sources (Health Canada, 2020a; Knaak \& Stuart, 2021; National Institute on Drug Abuse, 2020a). Participants were then asked to complete the LCR and political conservatism question. Using the Qualtrics' randomizer function, participants were then randomly assigned to one of six conditions: (1) male, no harm reduction condition; (2) female, no harm reduction condition; (3) male, OAT condition; (4) female, OAT condition; (5) male, SCS condition; (6) female, SCS condition. Participants were asked to read the vignette carefully and then complete the quantitative stigma measures, knowledge questions, and demographic questionnaire. At the end of the survey, they watched a debriefing video and were asked if they would like to submit their data to be used in the study.

\section{Results}

\section{Preliminary Analyses}

All quantitative analyses were conducted using IBM SPSS Statistics (version 26, IBM Corp., 2019). Before primary analyses were completed, the data was cleaned and analysis assumptions were checked. To examine relationships between the dependent variables (DVs; social distance, semantic differential, and attribution), a Pearson's correlation matrix was created (see Table 2). There were statistically significant positive correlations between all the dependent variables $(0.65 \leq|r| \leq 0.73$; $p$ s $<0.001)$, suggesting participants' attitudes towards the vignette character were consistent across measures. Regarding the two potential covariates, the LCR did not have adequate correlations with the DVs $(0.10 \leq r \leq 0.15$; see Table 2) to be suitable to include as a covariate (Becker, 2005), and thus was not included in the analyses. It was determined that political conservatism did have adequate correlations with all three dependent variables $(0.24 \leq|r| \leq 0.33$; $p \mathrm{~s}<0.001)$, and thus was included as a covariate in the primary analyses.

\section{Primary Analyses}

For the primary analyses, a 3 (harm reduction: no harm reduction, OAT, SCS) $\times 2$ (gender: male, female) between-subjects factorial analysis of covariance (ANCOVA) was conducted for each dependent variable (social distance, affect, and attribution) 
with political conservatism as the covariate. A Bonferroni adjusted alpha of 0.017 ( $\alpha=0.05 / 3$ ) was used to reduce the chance of type 1 errors due to the three independent ANCOVAs. Post-hoc pairwise comparisons were carried out with a further Bonferroni corrected alpha of $0.006(\alpha=0.017 / 3)$.

The social distance ANCOVA had a significant main effect for harm reduction, $F(2,321)=6.93, p=0.001, \omega^{2}=0.03$. Post-hoc pairwise comparisons revealed that the adjusted marginal mean in the no harm reduction condition $(M=2.97, S E=0.05)$ was significantly higher than in the OAT condition $(M=2.72, S E=0.05), M_{\text {diff }}=0.25$, $t(321)=3.57, p<0.001,95 \%$ CI $[0.12,0.39]$. The mean score for the SCS $(M=2.90$, $S E=0.05)$ was between these two conditions; however, it was not significantly lower than the no harm condition, $M_{\text {diff }}=0.08, t(321)=1.14, p=0.258,95 \% \mathrm{CI}[-0.06,0.22]$, or higher than the OAT condition, $M_{\text {diff }}=0.17, t(321)=2.43, p=0.014,95 \%$ CI [0.04, $0.31]$. There was no statistically significant main effect for gender, $F(1,321)=3.72$, $p=0.055$, nor an interaction between gender and harm reduction, $F(2,321)=1.15$, $p=0.317$.

The semantic differential ANCOVA had a significant main effect of harm reduction, $F(2$, $321)=5.88, p=0.003, \omega^{2}=0.03$, Post-hoc pairwise comparisons revealed that the adjusted marginal mean score in the no harm reduction condition $(M=3.66, S E=0.08)$ was higher than in the OAT condition $(M=3.27, S E=0.08), M_{\text {diff }}=0.39, t(321)=3.25, p=0.001,95 \%$ CI $[0.16,0.62]$. The mean score in the SCS condition $(M=3.53, S E=0.08)$ was between the OAT and no harm reduction conditions but was not significantly lower than no harm reduction, $M_{\text {diff }}=0.13, t(321)=1.08, p=0.277,95 \%$ CI $[-0.10,0.36]$, nor significantly higher than the OAT condition $M_{\text {diff }}=0.26, t(321)=2.17, p=0.025,95 \%$ CI $[0.03,0.49]$. There was no statistically significant main effect of gender, $F(1,321)=0.22, p=0.643$, and there was no interaction between gender and harm reduction, $F(2,321)=0.90, p=0.408$.

There was no significant main effect for gender for the attribution ANCOVA $F(1$, $321)=0.75, p=0.388$. The main effect of harm reduction did not meet statistical significance at the adjusted alpha, but did reach conventional statistical significance, $F(2$, $321)=3.40, p=0.034$, which yielded a small effect size $\left(\omega^{2}=0.01\right)$; the pattern of means was consistent with the other two ANCOVAs (i.e. social distance and semantic differential). That is, the mean score for the SCS condition $(M=4.44, S E=0.09)$ was lower than no harm reduction $(M=4.57, S E=0.09)$, but higher than OAT $(M=4.24$, $S E=0.09), p s \geq 0.010$. There was no significant interaction between gender and harm reduction, $F(2,321)=2.13, p=0.121$.

\section{Additional Analyses}

Means and standard deviations for quantitative questions asking about participants' self-rated knowledge of harm reduction, OAT, and SCSs were calculated (scores ranged from $1=$ no knowledge to $7=$ very knowledgeable). On average, participants reported having low knowledge when it came to the meaning of "harm reduction" $(M=2.74$, $S D=1.48)$, "opioid agonist therapy" $(M=2.06, S D=1.35)$, and "safe consumption sites" $(M=3.28, S D=1.59)$. The open-ended questions that followed each of these three questions were read carefully, with keywords and patterns identified, tallied, and discussed separately below. Since participants often listed multiple descriptions of what the three terms involved, keyword categories discussed below are not mutually exclusive (i.e. participants' responses can be included in one or more categories). 


\section{Knowledge of Harm Reduction}

Despite the lower quantitative average on this question, participants provided fairly accurate open-ended responses. Many participants said harm reduction was a way to decrease the harm associated with human behaviour in general $(30 \%, n=94)$ or regarding drug use specifically $(41 \%, n=130)$. However, $6 \%(n=19)$ of participants thought harm reduction was a path to abstinence and $6 \%(n=19)$ said that the goal of harm reduction was to reduce substance use entirely. For instance, one participant stated, "I think it just reduces the damage done from abusing opioids over time, helping people overcome their addiction". However, $12 \%(n=38)$ of participants explicitly stated that they did not know what harm reduction was.

\section{Knowledge of OAT}

In these responses, one third of participants $(33 \%, n=106)$ stated that they did not know what OAT was. Some participants $(13 \%, n=42)$ identified OAT as a treatment that would lead to abstinence. More specifically, $13 \%(n=41)$ of participants asserted that OAT is a treatment that helps people reduce drug use and $16 \%(n=51)$ indicated that OAT helps with symptoms of withdrawal from drugs. Additionally, 9\% $(n=29)$ of participants mentioned that OAT is a form of therapy (such as talk therapy) that people with SUDs partake in, in attempt to overcome addiction. Many participants $(28 \%, n=89)$ also mentioned that OAT is when you take a less harmful, alternative drug in replacement of the current problem opioid.

\section{Knowledge of SCSs}

Regarding SCSs, only $10 \%(n=33)$ of participants stated that they did not know what SCSs were; most participants acknowledged that it was a supervised place $(41 \%, n=132)$ where someone could use drugs in a safe $(44 \%, n=141)$ and hygienic $(11 \%, n=36)$ environment with medical care $(18 \%, n=59)$ being available to prevent fatal overdose. Students also mentioned that the main method of drug consumption at SCSs was through injection (11\%, $n=34)$. Although many answers suggested a partially accurate depiction of SCSs, $8 \%$ $(n=25)$ thought that SCSs provided the drugs (legal or illegal) and $4 \%(n=12)$ stated that staff helped with the administration of these drugs. For example, one participant stated that SCSs are "places where people can go to get opioids from a clean [sic] environment". Only a very small subset of answers said that SCSs are places where people go to be weaned off drugs $(2 \%, n=6)$ or where people go to get treatment for their addiction $(2 \%, n=6)$.

\section{Discussion}

Although there has been research conducted on the stigma of substance use, less research has examined opioid-related stigma specifically, and even less on harm reduction strategies. The purpose of the current study was to gain a better understanding of the public's attitudes and perceptions towards different harm reduction strategies. While no gender differences were found, the current study found that OAT was less stigmatized than no harm reduction. A numerical pattern demonstrated that SCSs were perceived more positively 
than no harm reduction and more negatively than OAT, but these differences did not reach statistical significance. Open-ended responses demonstrated that students held misconceptions about harm reduction.

The first two hypotheses predicted a main effect of harm reduction, in that the vignette character who visited the SCS would be the most stigmatized, followed by the character who did not engage in any harm reduction, with the character who engaged in OAT being the least stigmatized. H1a was supported, with participants wanting more social distance from and had more negative affect towards the character who did not engage in any harm reduction compared to the character who engaged in OAT.

$\mathrm{H} 1 \mathrm{~b}$ and $\mathrm{H} 2$ were not supported, as the stigma towards the character who visited a SCS was not significantly different from the other two conditions, although the differences in mean scores between SCSs and OAT did reach conventional levels of significance $(\alpha=0.05)$ for social distance $(p=0.014)$ and affect $(p=0.025)$. The SCS mean scores (for all dependent variables) were numerically lower than mean scores for no harm reduction and numerically higher than OAT mean scores, but these differences were not statistically significant. This consistent pattern across all measures might suggest that SCSs may be perceived more negatively than OAT but may be seen slightly more positively than no harm reduction. For instance, when Rosenberg and Phillips (2003) assessed the acceptability of various substance use interventions, they found that American addiction agencies saw short-term and long-term OAT as more acceptable than SCSs, as SCSs were viewed as sending the wrong message.

H3 predicted a main effect for gender, in that the male vignette character would be more stigmatized than the female character. This hypothesis was not supported, as results showed that there was no statistically significant main effect of gender across all dependent measures. Based on previous literature, these results were unexpected (Goodyear et al., 2018; Sattler et al., 2017; Weeks \& Stenstrom, 2020; Wirth \& Bodenhausen, 2009). One potential explanation could be that gender was not salient enough in the vignettes used in the current study, since only the name of the vignette character and their respective pronouns were changed.

These results could also be explained by the trends in gender differences when it comes to opioid use and fatal opioid-related overdoses. Although men are overly represented in opioid-related deaths, the death rate for women has been rapidly increasing. Between 1999 and 2010, fatal opioid overdose for women increased fivefold, while men's rates increased just over three and a half times (Centers for Disease Control and Prevention, 2013). For women aged 30-64 in the USA, between 1999 and 2017, there was an increase of 1,643\% in synthetic opioid overdose deaths and a $915 \%$ increase in heroin overdose deaths (VanHouten et al., 2019). It has also been shown that women are more likely to be prescribed opioids and are more likely to be given higher doses compared to men (Campbell et al., 2010; Terplan, 2017). Due to these emerging trends, opioid use problems may be viewed as more gender neutral; though, more research on this speculation is needed.

Findings from the qualitative data may help to explain why the only significant difference was OAT being less stigmatized than no harm reduction. When participants explained their understanding of OAT, $13.3 \%(n=42)$ thought OAT was a treatment that would lead to abstinence and $13.3 \%(n=42)$ thought the goal of OAT was to reduce drug use. Meanwhile, $1.9 \%(n=6)$ thought SCSs are places where people go to be weaned off drugs and another $1.9 \%(n=6)$ said SCSs are where those using substances go to treat their addiction. Since previous studies have demonstrated that society has an underlying belief that abstinence should be the ultimate goal and is the only acceptable solution to addiction (Csiernik et al., 2017; Richard et al., 2020; Watson et al., 2012), 
it is not surprising that participants viewed the harm reduction strategy most associated with recovery and treatment (OAT) in a less stigmatizing way than not engaging in any harm reduction at all as participants may have been less likely to stigmatize somebody who is assumed to be "on the road to recovery".

Although no other studies (to the researchers' knowledge) have directly compared attitudes towards different harm reduction strategies, the current results corroborate what has been found in previous literature when comparing levels of stigma more generally. For example, although OAT in the current study was the least stigmatized, overall stigma scores remained relatively high, with OAT scores hovering above the midpoint of the social distance scale, and near the midpoint of the semantic differential and attribution scales. This supports previous qualitative studies that have demonstrated that those who use OAT have felt very stigmatized by friends, family, the public, and healthcare providers (Bojko et al., 2016; Earnshaw et al., 2013; Fatani et al., 2021; Woo et al., 2017). A study by Gidman and Coomber (2014) also found that the public held negative and stigmatizing views towards those who used methadone, saw long-term methadone maintenance as a sign of treatment failure, and viewed methadone as a method that involved simply replacing one addictive drug with another.

\section{Implications}

Since past literature has found a positive correlation between support for harm reduction services and harm reduction knowledge (Baker et al., 2019), an educational stigma intervention for harm reduction should be considered. In a systematic review of stigma interventions by Tostes et al. (2020), due to methodological limitations, no conclusion could be drawn on the effectiveness of existing stigma interventions specific to substance use. Tostes et al. suggested that using less traditional educational approaches, such as social contact interventions, may be more effective. This was supported by a study that focused on reducing stigma towards those who use opioids specifically. Knaak et al. (2022) found that the use of a personal story intervention reduced stigma towards those who used opioids. Having policy makers create an intervention that combines addressing the misconceptions of harm reduction through education (e.g. emphasizing that the underlying goal of harm reduction is not abstinence), as well as including a social contact component (e.g. having an individual who uses harm reduction tell their story, share the benefits of harm reduction) that is directed towards the public, may prove beneficial.

Creating stigma interventions specific to harm reduction may better inform attitudes and hopefully alter current perceptions towards a more positive and supportive stance of harm reduction. For example, the current study found a trend in scores that suggested SCSs may be seen more negatively than OAT (though, these differences did not reach significance). If SCSs are truly viewed more negatively than OAT, it may prove beneficial to provide evidence-based facts on the benefits of SCSs, while dispelling common myths. This, in turn, would hopefully increase the community's knowledge of SCSs and reduce public stigma associated with accessing SCSs. This would hopefully help those using opioids feel less stigmatized when it comes to using any form of harm reduction, keeping in mind that stigma has shown to act as a major barrier to help-seeking, especially for those with substance use problems (Earnshaw et al., 2013; Lembke \& Zhang, 2015). 


\section{Strengths and Limitations}

The current study was the first (that the researchers are aware of) to empirically examine the stigma associated with different harm reduction strategies. Although the findings may not be generalizable to the public entirely (due to the use of a university student sample), strengths of the study included a large sample size, an equal gender split, and a diverse academic major sample (a total of 40 different majors had participated). Another strength of the study involved the use of open-ended responses, which can provide a deeper, richer understanding of what is being studied (Allen, 2017; Essess \& Maio, 2002); this can be beneficial when exploring a topic that has not been extensively researched (such as the public's understanding of and stigma towards harm reduction). The use of qualitative responses in the current study also aided in interpreting quantitative results, allowing for more holistic potential explanations for the findings.

The current study is not without limitations. Written vignettes are unable to completely capture elements of reality (Hughes, 1998); this raises a concern of whether or not written vignettes truly capture how a participant would act towards the vignette character in the real world (Hughes, 1998). Because of this, future research should consider using more realistic forms of manipulations, such as videos vignettes. Additionally, since this research was conducted during the COVID-19 pandemic, it could have influenced participants' willingness to interact with strangers, even fictitiously, impacting desire for social distance; however, social distance scores did correlate with the other dependent measures in our results, as well as the pattern of results was consistent across the three dependent measures.

Another limitation is that the current study used an undergraduate student sample that was enrolled in at least one psychology course and was almost exclusively under 30 years of age (97\%); additionally, over 50\% indicated that they were at least somewhat liberal and $29 \%$ identifying as moderate. Previous literature has demonstrated that those who are younger in age (Goodyear \& Chavanne, 2020), who identify as liberal (Broady et al., 2020; DeLuca \& Yanos, 2016), and who are more educated (Goodyear \& Chavanne, 2020; McLean et al., 2014) tend to have less stigmatizing attitudes towards those with a mental illness. Hence, a sample more representative of the Canadian population, and more diverse, should be used in future research.

\section{Future Directions}

For future research, it would be beneficial to extend the current findings by examining if other forms of bias play a role in harm reduction stigma. This includes bias related to race/ ethnicity, socioeconomic class, sexuality, age, or a combination of these demographics, as the interaction and cooccurrence of numerous stigmatized identities while having a substance use problem may yield different amounts or experiences of stigma (i.e. intersectional stigma; Bowleg, 2012; Turan et al., 2019). Thus, it would be beneficial to identify other factors that may contribute to stigma and act as a barrier to certain populations trying to access harm reduction services.

Additionally, the current study did not specify the problem opioid in the vignette, as the goal was to focus on the action of engaging in different harm reduction strategies. Perhaps future research could identify specific substances (e.g. heroin, codeine) and methods of use (e.g. injection, inhalation) when describing the vignette character's opioid use. There 
has been some evidence that stigma may vary depending on the type of opioid being used (Cooper, 2013; Goodyear et al., 2018; Weeks \& Stenstrom, 2020), how it is being consumed (Rhodes et al., 2007; Simmonds \& Coomber, 2009), how the opioid is obtained (Weeks \& Stenstrom, 2020), and how the opioid misuse started in the first place (Goodyear et al., 2018). This level of specificity could help improve the understanding of how opioidrelated stigma may manifest itself, or impact the stigma associated with accessing harm reduction, better informing attempts to reduce opioid-related stigma. Additionally, other stigma measures should be used to gain further understanding of opioid- and harm reduction-related stigma, such exploring the AQ-27's subscale scores separately or using different stigma scales (e.g. dangerousness scale).

As seen in the SCS qualitative responses, a small portion of participants assumed that SCSs are places where you go to obtain drugs, or where you go to have staff aid in administration of these drugs. Although these assumptions are false, they should be investigated further. It would be interesting to see where and how participants got these preconceived notions of SCSs. This information would be helpful to policymakers, as it would help further the knowledge of how the public views various harm reduction strategies, and where they may obtain these perceptions.

Author Contribution Gemma Reynolds contributed to all aspects of the study including conception and design, material preparation, data collection and analyses, and manuscript preparation. All other authors contributed to the design of the study, review of manuscript drafts, and approval of the final manuscript.

\section{Declarations}

Ethics Approval and Consent to Participate This study was approved by the University of Calgary's Conjoint Faculties Research Ethics Board (REB20-1381). Informed consent was obtained from all participants.

Conflict of Interest The authors declare no competing interests.

Disclosure of Interest Stephanie Knaak is an Associate Editor for the International Journal of Mental Health and Addictions and a Guest Editor for the special issue where this article appears. Andrew Szeto is also a Guest Editor for this special issue. The processing of this manuscript through the editorial process was handled by another editor for the journal. Neither authors were involved in any part of the editorial or acceptance processes for this article.

\section{References}

Aflakseir, A., Esini, M. R., Goodarzi, M., \& Molazadeh, J. (2019). Individuals with mental illness and stigma reduction: A cross-sectional study in a group of college students. Iranian Journal of Psychiatry, 14(4), 297-301. https://doi.org/10.18502/ijps.v14i4.1980

Alexander, L., \& Link, B. (2003). The impact of contact on stigmatizing attitudes toward people with mental illness. Journal of Mental Health, 12(3), 271-289. https://doi.org/10.1080/0963823031000118267

Allen, M. (Ed.). (2017). The sage encyclopedia of communication research methods. SAGE Publications. https://doi.org/10.4135/9781483381411

Baker, L. S., Smith, W., Gulley, T., \& Tomann, M. M. (2019). Community perceptions of comprehensive harm reduction programs and stigma towards people who inject drugs in Rural Virginia. Journal of Community Health, 45(2), 239-244. https://doi.org/10.1007/s10900-019-00732-8 
Barry, C. L., \& McGinty, E. E. (2014). Stigma and public support for parity and government spending on mental health: A 2013 national opinion survey. Psychiatric Services, 65(10), 1265-1268. https://doi. org/10.1176/appi.ps.201300550

Barry, C. L., McGinty, E. E., Pescosolido, B. A., \& Goldman, H. H. (2014). Stigma, discrimination, treatment effectiveness, and policy: Public views about drug addiction and mental illness. Psychiatric Services, 65(10), 1269-1272. https://doi.org/10.1176/appi.ps.201400140

Becker, T. E. (2005). Potential problems in the statistical control of variables in organizational research: A qualitative analysis with recommendations. Organizational Research Methods, 8(3), 274-289. https:// doi.org/10.1177/1094428105278021

Bojko, M. J., Mazhnaya, A., Marcus, R., Makarenko, I., Islam, Z., Filippovych, S., Dvoriak, S., \& Altice, F. L. (2016). The future of opioid agonist therapies in Ukraine: A qualitative assessment of multilevel barriers and ways forward to promote retention in treatment. Journal of Substance Abuse Treatment, 66, 37-47. https://doi.org/10.1016/j.jsat.2016.03.003

Bowleg, L. (2012). The problem with the phrase women and minorities: Intersectionality - an important theoretical framework for public health. American Journal of Public Health, 102(7), 1267-1273. https://doi.org/10.2105/AJPH.2012.300750

Broady, T. R., Brener, L., Cama, E., Hopwood, M., \& Treloar, C. (2020). Stigmatising attitudes towards people who inject drugs, and people living with blood borne viruses or sexually transmissible infections in a representative sample of the Australian population. PLOS ONE, 15(4), 1-13. https:// doi.org/10.1371/journal.pone.0232218

Brown, S. A. (2011). Standardized measures for substance use stigma. Drug and Alcohol Dependence, 116(1-3), 137-141. https://doi.org/10.1016/j.drugalcdep.2010.12.005

Burstein, P. (2003). The impact of public opinion on public policy: A review and an agenda. Political Research Quarterly, 56(1), 29-40. https://doi.org/10.1177/106591290305600103

Campbell, C. I., Weisner, C., LeResche, L., Ray, G. T., Saunders, K., Sullivan, M. D., Banta-Green, C. J., Merrill, J. O., Silverberg, M. J., Boudreau, D., Satre, D. D., \& Von Korff, M. (2010). Age and gender trends in long-term opioid analgesic use for noncancer pain. American Journal of Public Health, 100(12), 2541-2547. https://doi.org/10.2105/AJPH.2009.180646

Centers for Disease Control and Prevention (CDC). (2013). Vital signs: Overdoses of prescription opioid pain relievers and other drugs among women-United States, 1999-2010. MMWR. Morbidity and Mortality Weekly Report, 62(26), 537-542.

Centre for Addiction and Mental Health (2016). Opioid agonist therapy. https://www.camh.ca/-/media/ files/oat-info-for-clients.pdf

Cooper, R. J. (2013). "I can" t be an addict. I am.' Over-the-counter medicine abuse: A qualitative study. BMJ Open, 3(6). https://doi.org/10.1136/bmjopen-2013-002913

Corrigan, P. W., Druss, B. G., \& Perlick, D. A. (2014). The impact of mental illness stigma on seeking and participating in mental health care. Psychological Science in the Public Interest, 15(2), 37-70. https://doi.org/10.1177/1529100614531398

Corrigan, P. W., Markowitz, F. E., Watson, A., Rowan, D., \& Kubiak, M. A. (2003). An attribution model of public discrimination towards persons with mental illness. Journal of Health and Social Behavior, 44(2), 162-179. https://doi.org/10.2307/1519806

Corrigan, P. W., \& Rao, D. (2012). On the self-stigma of mental illness: Stages, disclosure, and strategies for change. The Canadian Journal of Psychiatry, 57(8), 464-469. https://doi.org/10.1177/ 070674371205700804

Corrigan, P. W., \& Shapiro, J. R. (2010). Measuring the impact of programs that challenge the public stigma of mental illness. Clinical Psychology Review, 30(8), 907-922. https://doi.org/10.1016/j.cpr. 2010.06.004

Csiernik, R., Rowe, W., \& Watkin, J. (2017). Prevention as controversy: Harm reduction. In R. Csiernik $\&$ W. S. Rowe (Eds.) Responding to the oppression of addiction: Canadian social work responses $\left(3^{\text {rd }}\right.$ ed., pp. 28-47). Canadian Scholars' Press.

Davis, S. M., Davidov, D., Kristjansson, A. L., Zullig, K., Baus, A., \& Fisher, M. (2018). Qualitative case study of needle exchange programs in the Central Appalachian region of the United States. PloS One, 13(10). https://doi.org/10.1371/journal.pone.0205466

Dear, M. (1992). Understanding and overcoming the NIMBY syndrome. Journal of the American Planning Association, 58(3), 288-300. https://doi.org/10.1080/01944369208975808

DeLuca, J. S., \& Yanos, P. T. (2016). Managing the terror of a dangerous world: Political attitudes as predictors of mental health stigma. International Journal of Social Psychiatry, 62(1), 21-30. https://doi.org/10.1177/0020764015589131 
Earnshaw, V., Smith, L., \& Copenhaver, M. (2013). Drug addiction stigma in the context of methadone maintenance therapy: An investigation into understudied sources of stigma. International Journal of Mental Health and Addiction, 11(1), 110-122. https://doi.org/10.1007/s11469-012-9402-5

Esses, V. M., \& Maio, G. R. (2002). Expanding the assessment of attitude components and structure: The benefits of open-ended measures. European Review of Social Psychology, 12(1), 71-101. https://doi.org/10.1080/14792772143000021

Fatani, S., Bakke, D., D’Eon, M., \& El-Aneed, A. (2021). Qualitative assessment of patients' perspectives and needs from community pharmacists in substance use disorder management. Substance Abuse Treatment, Prevention, and Policy, 16(1), 1-12. https://doi.org/10.1186/s13011-021-00374-X

Faul, F., Erdfelder, E., Buchner, A., \& Lang, A. G. (2009). Statistical power analyses using G* Power 3.1: Tests for correlation and regression analyses. Behavior Research Methods, 41(4), 1149-1160. https:// doi.org/10.3758/BRM.41.4.1149

Gidman, W., \& Coomber, R. (2014). Contested space in the pharmacy: Public attitudes to pharmacy harm reduction services in the West of Scotland. Research in Social and Administrative Pharmacy, 10(3), 576-587. https://doi.org/10.1016/j.sapharm.2013.07.006

Goodyear, K., \& Chavanne, D. (2020). Sociodemographic characteristics and the stigmatization of prescription opioid addiction. Journal of Addiction Medicine, 14(2), 150-155. https://doi.org/10.1097/ADM. 0000000000000552

Goodyear, K., Haass-Koffler, C. L., \& Chavanne, D. (2018). Opioid use and stigma: The role of gender, language and precipitating events. Drug and Alcohol Dependence, 185, 339-346. https://doi.org/10. 1016/j.drugalcdep.2017.12.037

Harm Reduction International. (n.d.). What is harm reduction? Retrieved November 23, 2020, from https:// www.hri.global/what-is-harm-reduction

Health Canada. (2020a). Opioids and the opioid crisis- Get the facts. Government of Canada. Retrieved November 23, 2020, from https://www.canada.ca/en/health-canada/services/substance-use/probl ematic-prescription-drug-use/opioids/get-the-facts.html

Health Canada. (2020b). Supervised consumption sites and services: Explained. Government of Canada. Retrieved November 23, 2020, from https:/www.canada.ca/en/health-canada/services/substance-use/ supervised-consumption-sites/explained.html

Henderson, C., Evans-Lacko, S., \& Thornicroft, G. (2013). Mental illness stigma, help seeking, and public health programs. American Journal of Public Health, 103(5), 777-780. https://doi.org/10.2105/AJPH. 2012.301056

Holmes, E. P., Corrigan, P. W., Williams, P., Canar, J., \& Kubiak, M. A. (1999). Changing attitudes about schizophrenia. Schizophrenia Bulletin, 25(3), 447-456. https://doi.org/10.1093/oxfordjournals.schbul. a033392

Hughes, R. (1998). Considering the vignette technique and its application to a study of drug injecting and HIV risk and safer behaviour. Sociology of Health \& Illness, 20(3), 381-400. https://doi.org/10.1111/ 1467-9566.00107

IBM Corp. (2019). IBM SPSS Statistics for Windows, Version 26.0. Armonk, NY: IBM Corp. [Computer software].

Javadi, R., Lagana, K., Krowicki, T., Bennett, D., \& Schindler, B. (2021). Attitudes toward harm reduction among substance use treatment professionals in Philadelphia. Journal of Substance Use, 1-6. https:// doi.org/10.1080/14659891.2021.1961320

Kennedy-Hendricks, A., Barry, C. L., Gollust, S. E., Ensminger, M. E., Chisolm, M. S., \& McGinty, E. E. (2017). Social stigma toward persons with prescription opioid use disorder: Associations with public support for punitive and public health-oriented policies. Psychiatric Services, 68(5), 462-469. https:// doi.org/10.1176/appi.ps.201600056

Knaak, S., Beshara, J., Billett, M., Kharpal, K., \& Patten, S. (2022). Measuring impacts of curricular content and personal story on substance use stigma. Journal of Nursing Education.

Knaak, S., Mantler, E., \& Szeto, A. C. H. (2017). Mental illness-related stigma in healthcare: Barriers to access and care and evidence-based solutions. Healthcare Management Forum, 30, 111-116. https:// doi.org/10.1177/0840470416679413

Knaak, S., Stuart, H. (2021). Measuring opioid-related stigma. In K. S. Dobson and H. Stuart (Eds.), The stigma of mental illness. Oxford University Press.

Lembke, A., \& Zhang, N. (2015). A qualitative study of treatment-seeking heroin users in contemporary China. Addiction Science and Clinical Practice, 10(1), 1-8. https://doi.org/10.1186/ s13722-015-0044-3

Link, B. G., Cullen, F. T., Frank, J., \& Wozniak, J. F. (1987). The social rejection of former mental patients: Understanding why labels matter. American Journal of Sociology, 92(6), 1461-1500. https://doi.org/ 10.1086/228672 
Link, B. G., \& Phelan, J. C. (2001). Conceptualizing stigma. Annual review of. Sociology, 27(1), 363-385. https://doi.org/10.1146/annurev.soc.27.1.363

Livingston, J. D. (2013). Mental illness-related structural stigma: The downward spiral of systemic exclusion final report. Mental Health Commission of Canada. https://www.mentalhealthcommission.ca/ sites/default/files/MHCC_OpeningMinds_MentalIllness-RelatedSructuralStigmaReport_ENG_0_0. pdf

Livingston, J. D. (2020) Structural stigma in health-care contexts for people with mental health and substance use issues: A literature review. Mental Health Commission of Canada. https://www.mentalheal thcommission.ca/sites/default/files/2020-07/structural_stigma_in_healthcare_eng.pdf

MacCoun, R. J. (1998). Toward a psychology of harm reduction. American Psychologist, 53(11), 11991208. https://doi.org/10.1037/0003-066X.53.11.1199

Mannarini, S., \& Boffo, M. (2015). Anxiety, bulimia, drug and alcohol addiction, depression, and schizophrenia: What do you think about their aetiology, dangerousness, social distance, and treatment? A latent class analysis approach. Social Psychiatry and Psychiatric Epidemiology, 50(1), 27-37. https://doi.org/10.1007/s00127-014-0925-x

Martínez-Hidalgo, M. N., Lorenzo-Sánchez, E., García, J. J. L., \& Regadera, J. J. (2018). Social contact as a strategy for self-stigma reduction in young adults and adolescents with mental health problems. Psychiatry Research, 260, 443-450. https://doi.org/10.1016/j.psychres.2017.12.017

McGinty, E. E., \& Barry, C. L. (2020). Stigma reduction to combat the addiction crisis - Developing an evidence base. New England Journal of Medicine, 382(14), 1291-1292. https://doi.org/10.1056/ nejmp2000227

McGinty, E. E., Barry, C. L., Stone, E. M., Niederdeppe, J., Kennedy-Hendricks, A., Linden, S., \& Sherman, S. G. (2018). Public support for safe consumption sites and syringe services programs to combat the opioid epidemic. Preventive Medicine, 111, 73-77. https://doi.org/10.1016/j.ypmed.2018. 02.026

McLean, S. A., Paxton, S. J., Massey, R., Hay, P. J., Mond, J. M., \& Rodgers, B. (2014). Stigmatizing attitudes and beliefs about bulimia nervosa: Gender, age, education and income variability in a community sample. International Journal of Eating Disorders, 47(4), 353-361. https://doi.org/10. 1002/eat.22227

Mushtaq, S., Mendes, V., Nikolaou, V., \& Luty, J. (2015). Analysis of the possible components of stigmatised attitudes towards depression and heroin dependence. Journal of Substance Use, 20(6), 399-406. https://doi.org/10.3109/14659891.2014.934306

National Institute on Drug Abuse (2020a). Prescription opioids DrugFacts. Retrieved November 16, 2020, from https://www.drugabuse.gov/publications/drugfacts/prescription-opioids

National Institute on Drug Abuse. (2020b). What are misconceptions about maintenance treatment? Retrieved November 16, 2020, from https://www.drugabuse.gov/publications/research-reports/ medications-to-treat-opioid-addiction/what-are-misconceptions-about-maintenance-treatment

OECD. (2019). Addressing problematic opioid use in OECD countries. OECD Publishing. https://doi. org/10.1787/a18286f0-en

Penn, D. L., Guynan, K., Daily, T., Spaulding, W. D., Garbin, C. P., \& Sullivan, M. (1994). Dispelling the stigma of schizophrenia: What sort of information is best? Schizophrenia Bulletin, 20(3), 567-578. https://doi.org/10.1093/schbul/20.3.567

Rhodes, T., Watts, L., Davies, S., Martin, A., Smith, J., Clark, D., Craine, N., \& Lyons, M. (2007). Risk, shame and the public injector: A qualitative study of drug injecting in South Wales. Social Science and Medicine, 65(3), 572-585. https://doi.org/10.1016/j.socscimed.2007.03.033

Richard, E. L., Schalkoff, C. A., Piscalko, H. M., Brook, D. L., Sibley, A. L., Lancaster, K. E., Miller, W. C., \& Go, V. F. (2020). "You are not clean until you're not on anything": Perceptions of medication-assisted treatment in rural Appalachia. International Journal of Drug Policy, 85, 102704. https://doi.org/10.1016/j.drugpo.2020.102704

Rosenberg, H., \& Phillips, K. T. (2003). Acceptability and availability of harm-reduction interventions for drug abuse in American substance abuse treatment agencies. Psychology of Addictive Behaviors, 17(3), 203. https://doi.org/10.1037/0893-164X.17.3.203

Sattler, S., Escande, A., Racine, E., \& Göritz, A. S. (2017). Public stigma toward people with drug addiction: A factorial survey. Journal of Studies on Alcohol and Drugs, 78(3), 415-425. https://doi. org/10.15288/jsad.2017.78.415

Simmonds, L., \& Coomber, R. (2009). Injecting drug users: A stigmatised and stigmatising population. International Journal of Drug Policy, 20(2), 121-130. https://doi.org/10.1016/j.drugpo.2007.09. 002 
Special Advisory Committee on the Epidemic of Opioid Overdoses (2021, June). Opioid and stimulant-related harms in Canada. Public Health Agency of Canada. Retrieved August 15, 2021, from https://health-infobase.canada.ca/substance-related-harms/opioids-stimulants

Stuart, H. (2019). Managing the stigma of opioid use. Healthcare Management Forum, 32(2), 78-83. https://doi.org/10.1177/0840470418798658

Terplan, M. (2017). Women and the opioid crisis: Historical context and public health solutions. Fertility and Sterility, 108(2), 195-199. https://doi.org/10.1016/j.fertnstert.2017.06.007

Tostes, J. G. D. A., Dias, R. T., Reis, A. A. D. S., Silveira, P. S. D., \& Ronzani, T. M. (2020). Intervenções para redução do estigma relacionado às pessoas que usam drogas: Revisão sistemática [Interventions to reduce stigma related to people who use drugs: Systematic review]. Paidéia (ribeirão Preto), 30, e3022. https://doi.org/10.1590/1982-4327e3022

Turan, J. M., Elafros, M. A., Logie, C. H., Banik, S., Turan, B., Crockett, K. B., Pescosolido, B., \& Murray, S. M. (2019). Challenges and opportunities in examining and addressing intersectional stigma and health. BMC Medicine, 17(1), 1-15. https://doi.org/10.1186/s12916-018-1246-9

VanHouten, J. P., Rudd, R. A., Ballesteros, M. F., \& Mack, K. A. (2019). Drug overdose deaths among women aged 30-64 years-United States, 1999-2017. Morbidity and Mortality Weekly Report, 68(1), 1-5. https://doi.org/10.15585/mmwr.mm6801a1

Watson, T. M., Bayoumi, A., Kolla, G., Penn, R., Fischer, B., Luce, J., \& Strike, C. (2012). Police perceptions of supervised consumption sites (SCSs): A qualitative study. Substance Use and Misuse, 47(4), 364-374. https://doi.org/10.3109/10826084.2011.645104

Weeks, C., \& Stenstrom, D. M. (2020). Stigmatization of opioid addiction based on prescription, sex and age. Addictive Behaviors, 108, 106469. https://doi.org/10.1016/j.addbeh.2020.106469

Wirth, J. H., \& Bodenhausen, G. V. (2009). The role of gender in mental-illness stigma: A national experiment. Psychological Science, 20(2), 169-173. https://doi.org/10.1111/j.1467-9280.2009.02282.x

Woo, J., Bhalerao, A., Bawor, M., Bhatt, M., Dennis, B., Mouravska, N., Zielinkski, L., \& Samaan, Z. (2017). "Don't judge a book by its cover": A qualitative study of methadone patients' experiences of stigma. Substance Abuse: Research and Treatment, 11, 11-12. https://doi.org/10.1177/1178221816 685087

Publisher's Note Springer Nature remains neutral with regard to jurisdictional claims in published maps and institutional affiliations. 